\title{
A Study on the Clinical Presentation of Hiv-Tb Coinfection and Its Correlation with Cd4 Count
}

\author{
DR.S.Malathi,MD*.,DR.S.Geetha,MD*.,DR.V.Madhavan,MD*. \\ DR.Vijay Usharaj.MD*., \\ *Assistant Professor, Department Of General Medicine, Government Royapettah Hospital/Kilpauk Medical \\ College, Chennai, Tamilnadu, India.
}

\begin{abstract}
Objectives: The aim of this study was to determine and compare the clinical presentation of pulmonary tuberculosis (PTB) and its correlation with CD4 count in groups of patients with and without human immunodeficiency virus (HIV) infection in ART \& CHEST clinic in kilpauk Medical College Hospital, Chennai, Tamilnadu, Chennai.

Materials and Methods: A total number of 60 patients of HIV + ve TB and 30 patients HIV -veTB were enrolled in this study. All patients were meticulously examined for the presence of Pulmonary and Extra pulmonary tuberculosis. Their symptoms were analyzed in a detailed manner. Complete general examinations for the presence of opportunistic infection and respiratory system and other system examination were done All of them were subjected to the following investigations. Basic blood investigation, sputum smear for AFB, chest $x$ ray PA view, PPD reactivity by mantaoux test and CD4 count. Special investigations were done in patients with extra pulmonary TB like FNAC of lymph node, biopsy, and CSF analysis

Results: Out of all participant males are commonly infected (68\%). the common age affected is between 36-45. pulmonary tuberculosis is most common than extra pulmonary $\mathrm{TB}(62 \% \mathrm{vs} 38 \%)$. On analyzing the sites of extra pulmonary $T B$ are occurs in the following orders- lymphnode(46.67\%), pleura(33.33\%), pericardium, meninges(6.67\%), GIT(46.67\%), GUT, bone(46.67\%) and others. On analyzing symptomatology of pulmonary $T B$, almost all the cardinal symptoms are present in both groups, but fever $(88.89 \%)$ and weight loss $(91.11 \%)$ are the commonest presenting symptoms of HIV-TB. Whereas, cough with expectoration(84.62\%) and hemoptysis(38.46\%) are common in non HIV-TB group. smear negative is more common in HIV$T B(78.3 \%) . H I V-T B$ patients often shows induration within 0-5 mm with mantoux test. Candidiasis is more commonly seen in HIV-TB patients( $38.33 \%)$.

Conclusion: As TB is the most common opportunistic infection in all HIV positive individuals, hence all HIV patients should be screened for TB and all TB patients should be screened for HIV status. males are more commonly infected. Tuberculosis has multiple clinical presentations in patients with HIV infection. Sputum smear negativity is more common, hence sputum culture is essential as a screening procedure. Mantoux test often is false negative in HIV-TB co infection. Lymphnodes, meninges and pleura are the common sites of extra pulmonary TB involvement. Tuberculosis can occur at any level of depletions of CD4 cout. Since TB-HIV fuel each other, early diagnosis And proper effective management are essential to reduce the morbidity and mortality.
\end{abstract}

\section{Introduction}

The burden of TB and HIV/ AIDS poses unprecedented challenges on the public health system in india. TB and HIV are overlapping epidemics. They are closely interlinked untreated HIV infection leads to progressive immunodeficiency and increased susceptibility to infections including TB. TB is the leading cause of HIV related morbidity and mortality. HIV is the most important factor fuelling the TB epidemics in populations with a high HIV prevalence in many countries especially in sub Saharan Africa and increasingly in Asia and South America. Studies have shown that there is close association between HIV and TB. Evidence of this interaction included several observations repeatedly made by WHO, National governments and funding partners. These observations are the areas that have been mostly affected by HIV epidemics also report the greatest increase in the incidence and prevalence of the TB.The largest increase in TB cases has occurred among people aged 25-40 years. The very same age group mostly affected by HIV/ AIDS.TB is the most common opportunistic infection among AIDS patients. (between 60-75\% of AIDS patients will develop TB) HIV prevalence among TB patients is higher than in the general population. (it is estimated a prevalence of $5.2 \%$ of HIV in adult TB in india. This study is focused to know about various clinical presentations of tuberculosis in HIV infected patients. As HIVTB co-infection leads to increased morbidity and mortality diagnosis of HIV-TB co-infection should be done at the earliest and thereby proper treatment, adequate care and support to be given all patients with HIV/ AIDS. 


\section{Aim}

To study the clinical presentation of tuberculosis in HIV positive patients and its correlation with CD4 count.

\section{Materials And Methods}

Place of study; Department of Medicine, Kilpauk Medical College Hospital, Chennai.

Type of study; Cross sectional study

Collaborating department; Chest clinic, ART clinic

Duration of study; January 2016 to January 2017.

\section{Case Selection}

\section{Inclusion criteria;}

1. patients who have been diagnosed as HIV positive either by Rapid test or ELISA and who have clinical and investigatory evidence of pulmonary TB or Extrapulmonary TB are enrolled in the study. These patients are picked up from ART clinic.

2. Those patients who sought medical attention for any form of tuberculosis at chest clinic OP, are chosen as controls

3. Patients between the age group of 15 to 55 are enrolled in the study.

\section{Exclusion criteria;}

1. Patients below the age of 15 and above the age of 55 are excluded in the study.

2. HIV positive individuals who did not have clinical or investigatory evidence of any form of TB were excluded.

3. Patients who had other causes of immune suppression such as diabetes, lymphoma, leukemia, visceral malignancy, malnutrition, on immune suppressive drugs were excluded.

\section{Clinical Examination}

\section{Methodology}

All HIV positive patients were meticulously examined for the presence of Pulmonary and Extra pulmonary tuberculosis. Their symptoms were analyzed in a detailed manner. Complete general examinations for the presence of opportunistic infection and respiratory system and other system examination were done All of them were subjected to the following investigations. Basic blood investigation, sputum smear for AFB, chest $\mathrm{x}$ ray PA view, PPD reactivity by mantaoux test and CD4 count. Special investigations were done in patients with extra pulmonary TB like FNAC of lymph node, biopsy, and CSF analysis.

\section{SPUTUM SMEAR FOR AFB}

\section{Done by ZiehlNeelsen technique;}

- Fix the the smear on the slide

- Cover the fixed smear with carbolfuchsin for 3 minutes

- Heat , rinse with tap water and decolorize with acid alcohol for 3-5 seconds

- Counterstain with methylene blue for 3-5 seconds

- Rinse again with tap water

- Observe under microscope by using oil immersion lens

The bacilli appears as red ,beeded rods, $2-5 \mu \mathrm{m}$ long and 0.25-0.5 $\mu \mathrm{m}$ wide. Minimum of three sputum samples ( 2 spot +1 early morning sample ) should be examined . results are read as follows.

\begin{tabular}{|l|l|l|}
\hline If the slide has & Results & Positive (grading) \\
\hline More than 10 AFB per oil immersion field & Positive & $3+$ \\
\hline 1-10 AFB per oil immersion field & Positive & $2+$ \\
\hline 10-99 AFB per 100 oil immersion field & Positive & $1+$ \\
\hline 1-9 AFB per 100 oil immersion field & Scanty & Record exact figure \\
\hline No AFB per 100 oil immersion field & Negative & - \\
\hline
\end{tabular}

In case of TB Lymphadenitis FNAC smear of the Lymphnode done and look for AFB.

2. Chest Skiagram

All the patient were taken x-ray chest PA views and if necessary lateral view. Infiltrations are carefully looked and also looked for cavitation, lymphnode enlargement either in mediastinum and /or hilar region. 


\section{Ppd Reactivity By Mantaux Test}

$0.1 \mathrm{ml}$ of purified protein derivative $-5 \mathrm{TU}$ injected intra dermally into the left forearm of the patients. The results are read at 48-72 hours later. In duration in the transverse axis is measured. Positive reactions indicate that the patients had been exposed to TB bacilli. In duration of more than $5 \mathrm{~mm}$ is indicative of TB infection in HIV infected patients.

\section{Csf Analysis}

In patients who had presented with signs of meningeal irritation or altered sensorium lumbar puncture was performed under aseptic precautions. CSF was subjected to cytology and bio chemical analysis. CSF analysis favoured TB meningitis.

\section{Cd4 Count Analysis}

Blood was collected in heparinized bottles for flow cytometry analysis. Blood was drawn in the morning and heparinized and was sent to Chennai Medical college for analysis of CD3, CD4 and CD8 counts by flowcytometry. Flow cytometry is used in the phenotyping of $\mathrm{T}$ cell subsets for monitoring of HIV patients.

\section{Procedure}

The heparinized blood of about $100 \mu 1$ of whole blood is simultaneously stained and analyzed for CD3 , CD4 and CD8 by FACS Count Cytometry using LASER.

\section{Results And Observations}

A total number of 60 patients of HIV + ve TB and 30 patients HIV -veTB were enrolled in this study. All the data were fed into a computer and the results were collected using an epidemiology incorporated software.

\section{The following test statistics were used}

1) Two sample $t$ test

2) Wilcoxon Rank Sum test / Mann- Whitney test

3) Chi-square test

4) Fisher- exact

Table 1- Sex Distribution Analysis

\begin{tabular}{|l|l|l|l|l|}
\hline & Male & & FEMALE & \\
\hline & No & $\%$ & No & $\%$ \\
\hline $\begin{array}{l}\text { Total No Of Cases Hiv } \\
\text { Positive Tb }\end{array}$ & 41 & 68.33 & 19 & 31.67 \\
\hline $\begin{array}{l}\text { Total No Of Hiv Negative } \\
\mathrm{Tb}\end{array}$ & 23 & 76.67 & 7 & 23.33 \\
\hline
\end{tabular}

On analyzing the sex distribution males are more commonly infected than femles in both the groups.

Table 2 - Age Distribution Analysis

\begin{tabular}{|l|l|l|l|l|}
\hline Age Group In Years & $\begin{array}{l}\text { Hiv +Ve Tb (60) } \\
\text { Male }\end{array}$ & $\begin{array}{l}\text { Hiv +Ve Tb (60) } \\
\text { Female }\end{array}$ & $\begin{array}{l}\text { Hiv- Ve Tb } \\
(30) \\
\text { Male }\end{array}$ & $\begin{array}{l}\text { Hiv-Ve Tb (30) } \\
\text { Female }\end{array}$ \\
\hline $15-25$ & 2 & 4 & 4 & 0 \\
\hline $26-35$ & 13 & 12 & 6 & 6 \\
\hline $36-45$ & 23 & 2 & 9 & 1 \\
\hline $46-55$ & 3 & 1 & 4 & 0 \\
\hline Mean Age & 35.95 & 28.84 & 33.78 & 27.71 \\
\hline S.D & 6.492 & 5.22 & 10.335 & 4.498 \\
\hline P' & 0.000099 & 0.000099 & 0.14575 & 0.14575 \\
\hline
\end{tabular}

On analyzing the age distribution the common age affected is between $36-45$.

Table 3- Clinical Presentation Of Tuberculosis

\begin{tabular}{|l|l|l|ll|}
\hline & Total no of cases & No of pulmonary tuberculosis & $\begin{array}{l}\text { No of extra pulmonary } \\
\text { tuberculosis }\end{array}$ \\
\hline HIV +ve & 60 & 45 & 15 & \\
\hline HIV -ve & 30 & 26 & 4 & \\
\hline
\end{tabular}

On analyzing the presentation of TB, pulmonary tuberculosis is most common than extra pulmonary TB. 


\section{Picture- Clinical Presentation Of Tuberculosis}

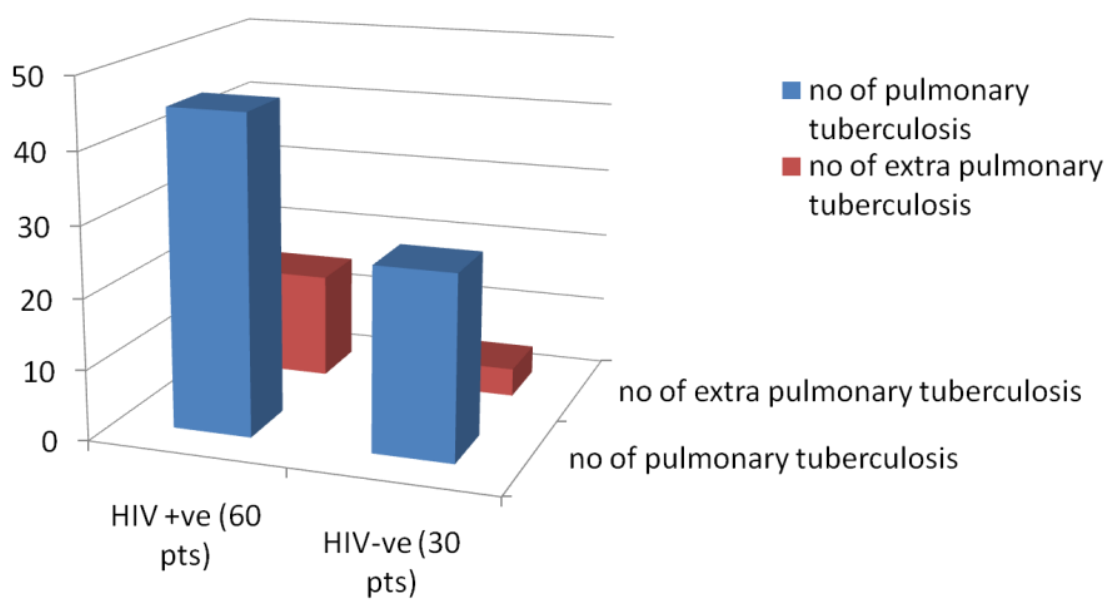

Table 4- presenting sites of extra pulmonary tb

\begin{tabular}{|l|l|l|l|l|l|}
\hline Presenting sites & $\begin{array}{l}\text { HIV +ve } \\
\text { No }\end{array}$ & $\begin{array}{l}\text { HIV +ve } \\
\%\end{array}$ & $\begin{array}{l}\text { HIV - ve } \\
\text { No }\end{array}$ & $\begin{array}{l}\text { HIV - ve } \\
\%\end{array}$ & P' valve \\
\hline TB lymphadenitis & 7 & 46.67 & 1 & 25 & 0.4257 \\
\hline $\begin{array}{l}\text { Tuberculous pleural } \\
\text { effusion }\end{array}$ & 5 & 33.33 & 1 & 25 & 0.6272 \\
\hline $\begin{array}{l}\text { Tuberculous } \\
\text { meningitis }\end{array}$ & 1 & 6.67 & 2 & 25 & 0.9701 \\
\hline G.I. tract TB & 1 & 46.67 & 0 & 0 & 0.7895 \\
\hline Bone & 1 & 46.67 & 0 & 0 & 0.7895 \\
\hline & & & & & \\
\hline
\end{tabular}

On analyzing the sites of extra pulmonary TB are occurs in the following orders- lymphnode, pleura, pericardium, meninges, GIT, GUT, bone and others.

Table 5-Symptom Analysis Of Pulmonary Tuberculosis

\begin{tabular}{|l|l|l|l|l|l|}
\hline Presenting symptoms & $\begin{array}{l}\text { HIV +ve } \\
\text { No }\end{array}$ & $\begin{array}{l}\text { HIV + ve } \\
\%\end{array}$ & $\begin{array}{l}\text { HIV -ve } \\
\text { No }\end{array}$ & $\begin{array}{l}\text { HIV -ve } \\
\%\end{array}$ & P' valve \\
\hline Fever & 40 & 88.89 & 11 & 42.31 & 0.00001313 \\
\hline Weight loss & 41 & 91.11 & 14 & 53.85 & 0.0004408 \\
\hline $\begin{array}{l}\text { Cough } \\
\text { expectoration }\end{array}$ & 36 & 80.00 & 22 & 84.62 & 0.001663 \\
\hline Hemoptysis & 3 & 6.67 & 10 & 38.46 & 0.001436 \\
\hline Dysnoea & 1 & 2.22 & 1 & 3.85 & 0.6016 \\
\hline Chest pain & 1 & 2.22 & 0 & 0.00 & 0.6016 \\
\hline
\end{tabular}

PRESENTATION OF SYMPTOMS IN TB PATIENTS
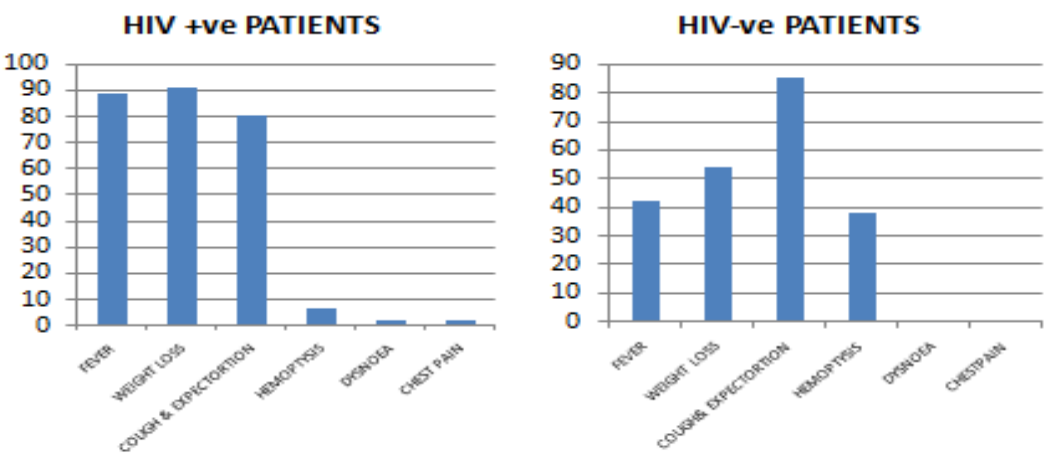
On analyzing symptomatology of pulmonary TB, almost all the cardinal symptoms are present in both groups, but fever and weight loss are the commonest presenting symptoms of HIV-TB. Whereas, cough with expectoration and hemoptysis are common in non HIV-TB group.

Table 6- Sputum Afb Analysis

\begin{tabular}{|l|l|l|}
\hline & HIV +ve TB (60) & HIV -ve TB (30) \\
\hline Sputum AFB +ve & 13 & 20 \\
\hline Sputum AFB -ve & 47 & 10 \\
\hline
\end{tabular}

On analyzing sputum AFB results, smear negative is more common in HIV-TB.

Table 7-Ppd Reactivity By Mantoux Test

\begin{tabular}{|l|l|l|}
\hline Measurement in mm & HIV +ve TB (60) & HIV -ve TB (30) \\
\hline $0-5$ & 44 & 1 \\
\hline $6-10$ & 14 & 8 \\
\hline $11-15$ & 2 & 12 \\
\hline$>15$ & 0 & 9 \\
\hline MEAN & 2.9 & 12.8 \\
\hline S.D & 4.1198 & 4.0034 \\
\hline P' & 0.000 & 0.000 \\
\hline
\end{tabular}

On analyzing the PPD reactivity by mantoux test, HIV-TB patients often shows induration within $0-5 \mathrm{~mm}$.

Table 8 - Cd4 Correlation With Clinical Presentations

\begin{tabular}{|l|l|l|l|}
\hline Type & MEAN CD4 COUNT & S.D & P' VALVE $^{\prime}$ \\
\hline Pulmonary TB & 174.2 & 139.0238 & 0.0289 \\
\hline Extra pulmonary TB & 114.6 & 116.6201 & 0.0289 \\
\hline
\end{tabular}

Table 9 - Incidence Of Opportunistic Infections In Hiv-Tb Patients

\begin{tabular}{|l|l|l|}
\hline TYPE & NO OF CASES (60) & $\%$ \\
\hline Candidiasis & 23 & 38.33 \\
\hline Herpes simplex & 4 & 6.67 \\
\hline Herpes zoster & 5 & 8.33 \\
\hline Perifolliculitis & 1 & 1.67 \\
\hline Scabies & 6 & 10 \\
\hline
\end{tabular}

Candidiasis is the most common opportunistic infection in HIV-TB patients.

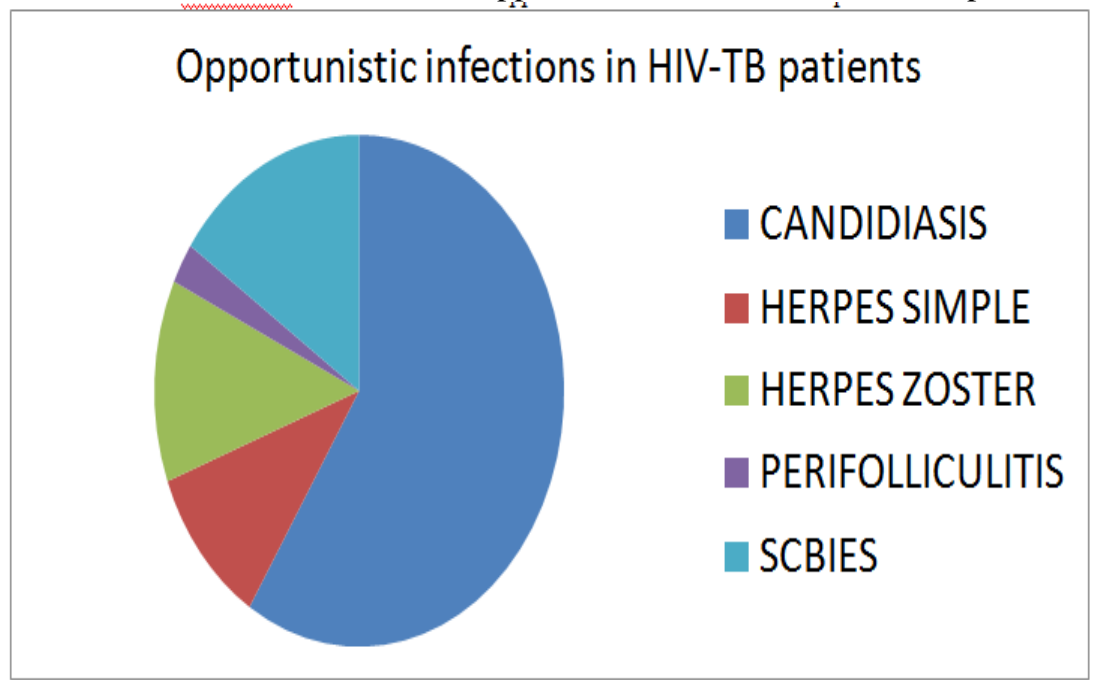

\section{Discussion}

$\mathrm{TB}$ is the most common opportunistic infection in HIV / AIDS patients. TB and HIV fuel each other, hence untreated HIV-TB co infection further increases the morbidity and mortality in HIV/ AIDS patients. So early diagnosis is very necessary to prevent the morbidity and mortality. This study documents the various clinical presentations of TB among HIV and non HIV patients. The x- ray presentation, sputum AFB, mantoux reactivity were analysed in both these groups. 
The observations made in these studies that males were commonly infected when compared to females. The mean age group for male 35.95 and female 28.84 in the HIV group and mean age group for male is 33.78 and female is 27.71 in non HIV -TB group. Out of 60 cases of HIV-TB , 45 cases are pulmonary TB , 15 cases are extra pulmonary TB and among 30 cases of non HIV-TB, 26 cases are pulmonary TB, 4 cases are extra pulmonary TB. There is no significant correlation. But various studies show that even in HIV / AIDS pulmonary TB is the most common. It basically depends on the level of patients immunosuppression. When TB occurs in the earlier period of HIV infection, pulmonary TB is more common. When TB occurs late in the period HIV infection, i.e after a significantly depressed CD4 count, extra pulmonary TB is more common. Sometimes both pulmonary and extra pulmonary TB may co-exist in the same patient.

On analyzing the extra pulmonary TB, out of 15 cases, 7 cases are TB Lymphadenitis, 5 cases are pleural effusion, 1 is TBM, 1 is GIT, 1 is bone. The various studies also document the site of EPTB are in the same order of occurance like lymphnode, pleura, pericardium, meninges, GIT, GUT, bone and others. Dr. Fitz Gerald, Dr.Stan et al university of coloumbia have noted these points. On analyzing symptomatology of pulmonary TB, almost all the cardinal symptoms are present in both groups, but fever and weight loss are the commonest presenting symptoms of HIV-TB i.e about $88 \%$ and $91 \%$ respectively. Whereas, cough with expectoration and hemoptysis are common in non HIV-TB group i.e about $80 \%$ and $46 \%$. Hemoptysis is present only in $6 \%$ in HIV group. This symptom analysis has significant $\mathrm{P}^{\prime}$ valveDyspnoea, chest pain have no significant differences in presentation in both groups. The reason being cough and hemoptysis are less common in HIV group is due to less cavitation and less bronchial irritation. One study conducted by Dr. Sowmyaawaminathan, Dr.Rajasekaran, Dr.S.Sangeetha et al, TRC, Chennai also stated the same point.

Lower zone infiltration was 10 out of 45 patients in HIV-TB group whereas 1 Case was found in non HIV-TB . The p' valve is 0.03636 which is significant. Various other studies also shown this atypical presentation in high percentage. This is very much consistent with observation made by ZumlaMalon and Henderson et al. They have found $50 \%$ of cases are having mediastinaladenopathy. Similar observation also documented by DianevHavlir, Peter F. Branes M.D. et al.

Regarding sputum AFB analysis, 13 out of 60 cases in HIV-TB, 20 out of 30 in non HIV-TB are smear positive for AFB. The p' valve is 0.00001 which is signifdicant. This is consistent with observation made out by ZumlaMalon and Hendersen et al .The reason being less sputum smear positivity in HIV/ TB is due to less cavity formation.. sputum smear negativity alone does not indicate absence of tuberculosis infection. Ideally these patients should be subjected to sputum culture and sensivity. Even more this bronchoscopy, BAL, Transbronchial biopsy may be needed to prove smear positivity.

Regarding PPD reactivity by mantoux test the mean induration in HIV-TB patients are $2.9 \mathrm{~mm}$ whereas non HIV-TB , mean induration is $12.8 \mathrm{~mm}$. the p' value is 0.00 which is significant. ZumlaMalon and Hendersen et al also insisted negative TB are more common in HIV positive individuals. Mark FitzGerald MD and Stan Houston, MD et al observed in his study stated that false negative tuberculosis test more likely in a HIV patients and is increasingly more common with increasing immunosuppression. Kothari et al stated that induration $5 \mathrm{~mm}$ following injection of tuberculin is taken as positive test for TB in HIV infected individuals.

On analyzing CD4 count the mean CD4 count of 45 out of 60 cases of pulmonary HIV-TB is 174.2 whereas the mean CD4 15 out of 60 cases of extra pulmonary HIV-TB IS 114.6. The p' value is 0.0285 which is significant. This is consistent with the observation made out of Post FA, Wood R , Pillay GP et al in south Africa and various other authors also. Infect tuberculosis can develop at any CD4 count. If the CD4 count is moderately low pulmonary tuberculosis is common. But when the CD4 count is very much lowered extra pulmonary tuberculosis is more common than pulmonary TB. Moreover atypical mycobacterial lesions and opportunistic infections are common.

\section{Conclusion}

As TB is the most common opportunistic infection in all HIV positive individuals, hence all HIV patients should be screened for TB and all TB patients should be screened for HIV status. males are more commonly infected. Tuberculosis has multiple clinical presentations in patients with HIV infection . Sputum smear negativity is more common, hence sputum culture is essential as a screening procedure. Mantoux test often is false negative in HIV-TB co infection. Lymphnodes, meninges and pleura are the common sites of extra pulmonary TB involvement. Tuberculosis can occur at any level of depletions of CD4 cout. Since TB-HIV fuel each other, early diagnosis And proper effective management are essential to reduce the morbidity and mortality.

\section{Bibiliography}

[1]. Corbett EL, Watt CJ. Walker N, Maher D, Williams BG. The growing burden of tuberculosis; global trends and interactions with HIV epidemic ( Archives of int medicine 2003, 163;1009-1021)

[2]. A clinical manual on HIV / TB ( second edition) by WHO, GENEVA, 2004.

[3]. UNAIDS- Updated on Global facts and figures (Dec 2006). http://data.unaids.org/pub/epireport/2006. 
[4]. WHO Global tuberculosis control: surveillance, planning, financing report 2007, Geneva, WHO, 2007(WHO/HTM/TB/2007/376)

[5]. TB India 2007-RNTCP status Report published central TB division, directorate general of public services, Ministry of Health \& Family Welfare, New Delhi.

[6]. Impact of HIV on tuberculosis in Zambia; a cross sectional study -A M Elliot, N Luo, G Tembo, B Halwiindi, G Steenbergen, L Machiels, J Pobee, P Nunn, R J Hayes , and K P Mc Adam. BMJ 1990 September1: 301(6749); 412-415.

[7]. Jamal LF, Moherdaui F (2007) Tuberculosis and HIV infection in Brazil: magnitude of the problem and strategies for control. Rev Saúde Pública 41: 104-110.

[8]. Greenberg SD, Frager D, Suster B, Walker S, Stavropoulos C, et al. (1994) Active pulmonary tuberculosis in patients with AIDS: spectrum of radiographic findings (Including a normal appearance). Radiology 193: 115-119.

[9]. Long R, Maycher B, Scalcini M, Manfreda J (1992) The chest roentgenogram in pulmonary tuberculosis patients seropositive for human immunodeficiency virus type I. Chest 99: 123-127.

[10]. Guidelines for Prevention and Treatment of Opportunistic Infections in HIV-Infected Adults and Adolescents Morbidity and Mortality. Weekly Report 58: 5. (2011) Tuberculosis National Institute for Health and Clinical Excellence.

[11]. 11. Elliott AM, Halwiindi B, Hayes RJ, Luo N, Tembo G, et al. (1993) The impact of human immunodeficncy virus on the presentation and diagnosis of tuberculosis in a cohort study in zambia. J Trop med hyg 96: 1-11 .

[12]. Bakari M, Arbeit RD, Mtei L, Lyimo J, Waddell R, et al. (2008) Basis for treatment of tuberculosis among HIV-infected patients in Tanzania: the role of chest X-ray and sputum culture. BMC Infect Dis 8: 32.

[13]. Noronha D, Pallangyo KJ, Ndosi BN, Lweno H, Sabuka SR (1991) Radiological features of pulmonary tuberculosis in patients infected with human immunodeficiency virus. East Aft Med J 68: 210-215.

[14]. Saks AM, Posner R (1992) Tuberculosis in HIV positive patients in South Africa: a comparative radiological study with HIV negative patients. Clin Radiol 46: 387-390.

[15]. Padyana M, Bhat RV, Dinesha M, Nawaz A (2012) HIV-Tuberculosis: A Study of Chest X-Ray Patterns in Relation to CD4 Count. N Am J Med Sci 4: 221-225.

[16]. Keiper MD, Beumont M, Elshami A, Langlotz CP, Miller WT Jr (1995) CD4 T lymphocyte count and the radiographic presentation of pulmonary tuberculosis. A study of the relationship between these factors in patients with human immunodeficiency virus infection. Chest 107: 74-80

[17]. Post FA, Wood R, Pillay GP (1995) Pulmonary tuberculosis in HIV infection: radiologic appearance is related to CD+ Tlymphocyte count. Tuberc Lung Dis 76: 518-521.

[18]. Ahmad Z, Shameem M (2005) Manifestation of tuberculosis in HIV infected patients. JIACM 6: 302-305

[19]. Prasad R, Saini JK, Gupta R, Kannaujia RK, Sarin S, et al. (2004) A comparative study of Clinico-radiological spectrum of tuberculosis among HIV Seropositive and HIV seronegative patients. Indian J Chest Dis Allied Sci 46: 99-103

[20]. Mabiala Babela JR, Makosso E, Senga P (2006) Radiological Specify of pulmonary tuberculosis in Congolese children: effect of HIV infection. Med Trop 66: 255-259.

[21]. Awoyemi OB, Ige OM, Onadeko BO (2002) Pattern of active pulmonary tuberculosis in human immunodeficiency virus seropositive adult patients in University College Hospital, Ibadan, Nigeria. Afr J Med Med Sci 31: 25-31.

[22]. Bellamy R, Ruwende C, Corrah T, McAdam KP, Whittle HC, et al. (1998) variations in the NRAMPI gene and susceptibility to tuberculosis in West Africans. N Engl J Med 338: 640-644. 